\title{
Risk factors associated with early mortality after percutaneous endoscopic gastrostomy in patients at a tertiary care center in Brazil: a retrospective single-center survival study
}

\author{
Luiz Eduardo MIRANDA ${ }^{1}$, Marcel Rolland Ciro da PENHA ${ }^{1}$, Ana Clara Galindo MIRANDA², \\ Diego Laurentino LIMA ${ }^{1}$, Matheus Wanderly Fernandes COSTA2 ${ }^{2}$ and Alexandre de Oliveira AMORIM ${ }^{2}$
}

Received 22/8/2019

\begin{abstract}
Background - Percutaneous endoscopic gastrostomy (PEG) is the main accepted method for long-term tube feeding. Objective - To investigate the risk factors associated with early mortality after PEG. Methods - Retrospective survival analysis in a tertiary-level center in Recife, Brazil. We reviewed the medical records of 150 patients with PEG placement. The data were analysed by the Kaplan-Meier method. Multivariable Cox proportional regression models were also built to test the effects of PEG on mortality. Results - A total of 150 patients who submitted to PEG were studied (70 male). Of the participants, 87 (58\%) had blood hypertension; 51 (34\%) patients had diabetes; 6 (4\%) patients had chronic renal disease; and $6(4 \%)$ had malignancy. Chronic neurodegenerative diseases were the more common clinical indication for PEG. The 30-day and 60-day proportional mortality probability rates were $11.05 \%$ and $15.34 \%$ respectively. A multivariate Cox proportional regression model, haemoglobin (HR $4.39,95 \%$ CI $1.30-14.81, P=0.017$ ) and pre-procedure UCI staying (HR $0.66,95 \%$ CI $0.50-0.87, P=0.004$ ) were significant predictors of early mortality. A haemoglobin cut-off value of $10.05 \mathrm{~g} / \mathrm{dL}$ was shown to have a sensibility of $82.6 \%(61.2 \%$ to $95 \% \mathrm{CI})$ and an acceptable sensitivity of $59.0(50.6 \%$ to $68.6 \% \mathrm{CI}$ ), and a likelihood ratio of 2.06 for eight weeks mortality. Conclusion - In patients who had been subjected to the PEG procedure for longterm nutrition, low haemoglobin, pre-procedure intensive care unit internment or both are associated with the risk of early mortality.
\end{abstract}

HEADINGS - Deglutition disorders. Malnutrition. Enteral nutrition. Critical illness. Dementia.

\section{INTRODUCTION}

Percutaneous endoscopic gastrostomy (PEG) was first performed by Gauderer and colleges in $1999^{(1)}$ and rapidly became the main support of nutritional care for patients with long-term swallowing dysfunction ${ }^{(2)}$. PEG is thought to be a more acceptable choice to deliver food than nasogastric tube because it is not associated with uncomfortable oropharyngeal symptoms and has better aesthetic appeal ${ }^{(3)}$. As opposed to nasogastric feeding, PEG use decreases the incidence of complications such as esophageal esophagitis and respiratory infections, resulting in lower risk of occlusion and dislocation and better compliance ${ }^{(4)}$. An increasingly common indication for PEG placement is the nutritional support provided to older patients who have lost their ability to eat because of cerebrovascular diseases, or who have severe incapability due to neurological chronic disease or advanced dementia ${ }^{(2,3,3,6)}$.

Although PEG placement is safe ${ }^{(7)}$, it is not free from the risk of mortality nor devoid of early severe complications, including bleeding, peritonitis, bowel obstruction or perforation, and abscess of operative wound ${ }^{(4,8)}$. Therefore, studies worldwide have failed to demonstrate benefits of PEG tube in older patients ${ }^{(9,10)}$. In case of in-hospital and 30-day postoperative stages, mortality can be as high as $10.3 \%$ and $54 \%$ respectively ${ }^{(11-15)}$, especially in hospitalized patients, although the procedure-related mortality itself is $0.5 \%$ to $2 \%$. Indicating the procedure to a patient who naturally dies a few days after it is a bad decision ${ }^{(7,16,17)}$. Therefore, it is imperative to improve PEG indication to choose only those patients who actually have a chance of benefiting from it, thereby voiding futile indications $\mathrm{s}^{(6,18)}$.

We reviewed our experience with PEG placement at a private tertiary-care Brazilian hospital and investigated independent variables associated with early mortality after PEG, considering only simple clinical and laboratory variables easily found for most patients.

\section{METHODS}

\section{Patients}

Patients with swallow dysfunction treated with PEG between January 2012 and December 2016 at the Unimed Recife Hospital were retrospectively studied from an electronic database. This is a tertiary-care hospital which works for a cooperative of medical services as a unit of supplementary health service in Brazil. This hospital is highly certified by the Canadian Council for Health Service Accreditation because of the quality of its clinical protocols

Declared conflict of interest of all authors: none

Disclosure of funding: no funding received

${ }^{1}$ Universidade de Pernambuco, Hospital Universitário Oswaldo Cruz, Departamento de Cirurgia Geral e Transplante Hepático, Recife, PE, Brasil. ${ }^{2}$ Universidade de Pernambuco, Faculdade de Ciências Médicas, Recife, PE, Brasil.

Corresponding author: Diego Laurentino Lima. E-mail: dilaurentino@gmail.com 
and patient security. It has an electronic medical records system that has the highest level of certification by the Healthcare Information and Management System Society.

Data were collected from adults, of both genders, requiring long-term enteral nutrition that has been submitted to first PEG placement. Outpatients, patients whose chart records were incomplete, and patients who had submitted to PEG replacement and those whose procedure had not been unsuccessful were excluded.

No dysphagia score was used. PEG placement was indicated by the doctor responsible for the patient through clinical observation that he/she was no longer able to feed themselves or with the help of another person and that he/she was dependent on tube feeding. The patient or his/her family, if the patients could not decide for themselves, was informed about advantages, disadvantage, risk, costs and potential clinical or surgical complications related to PEG placement and authorized it.

The following variables were collected: gender, age, mean diagnosis (e.g., Parkinson disease, sequels of stroke, dementia, tumours, and senility), comorbidities (diabetes mellitus, arterial hypertension, and renal insufficiency), laboratory exams (urea, haemoglobin), pre- and post-operative hospitalization in intensive care unit (ICU), orotracheal tube procedure, tracheostomy and dialysis (considering a period of two months before and after the procedure), the presence of surgical complications, diagnosis of the underlying disease, the endoscopy report and the time of survival.

\section{Surgical technique}

All procedures were performed by the same surgical team (MRCP, the surgeon and LECM, the endoscopist, both experienced) who ensured the well being of the patient until the moment of discharge and were responsible for the medical records. The support of an anaesthesiologist was indicated when necessary and at the discretion of the medical team.

Immediately prior to the initiation of the procedure, $2 \mathrm{~g}$ of cefazolin was injected intravenously as a prophylactic antibiotic, unless the patient was already taking antibiotics for another reason. Two puffs of $10 \%$ xylocaine spray were released in the oropharynx. Sedation was done with $50 \mu \mathrm{g}$ fentanyl and $1 \%$ propofol by the surgical team or with the anaesthesiologist's assistance when necessary and slowly until reaching the desired sedation plan.

All patients received oxygen via nasal catheter or tracheostomy and were monitored for pulse oximetry, blood pressure, and heart rate and frequency. The procedure was performed in an endoscopy room that meets the requirements of Brazilian legislation for an endoscopic centre. PEG was performed by the traction method using a standard forward-view endoscope (GIFH-180; Olympus America, Center Valley, PA). Upon endoscopic observation, a place in the anterior wall of the distal fornix was chosen and a puncture was made at this point through the abdominal wall using a needle 16 gauge until it reached the stomach lumen. Through this needle was delivered a guide wire, which was taken by a loop and externalized via the patient's mouth. This guide was attached to a PEG tube. The surgeon drew the guide wire through the abdominal wall, taking the tube from the mouth to the stomach and externalizing it through the abdominal wall. A silicone dome at the end of the probe prevents it from being drawn out of the stomach. The external bolster of the PEG kit was placed, keeping the probe attached to the abdominal wall and the stomach in juxtaposition to the inner abdominal wall. This creates a fistula between the stomach and the external environment through which the patient can be fed. The round external bolster was fixed to the skin with 3.0 nylon stitches and the same wire was attached to the gastrostomy tube, preventing it from moving into the abdomen. The stitches were removed by the surgical team itself 48-72 hours after the procedure and the tube was loosened by $0.5 \mathrm{~cm}$ to avoid the buried bumper syndrome. The patients were kept under observation of the responsible team until recovery from sedation and then sent to the hospital sector of origin. Six hours after the procedure, as long as no postoperative complications were observed, feeding was allowed partially by the gastrostomy tube, and after 24 hours, they were fed according to the nutritional demands of each patient.

Either an EndoViveTM enteral access initial placement system (24Fr Peg-Kit, Boston Scientific, Marlborough Mass, USA) or a PEG $24^{\circledR}$ Pull Method Kit (Cook Endoscopy, Indiana, USA) was used at the endoscopist's judgment.

Follow ups were conducted with each patient by the medical staff until the hospital discharge. The caregiver was instructed in the handling and maintenance of the gastrostomy cannula in order to avoid complications such as buried bumper syndrome or tube avulsion.

The following complications were defined: Buried bumper syndrome - migration of the silicone dome alongside the track of the stoma outside the stomach, occluding the gastric orifice; abscess - purulent drainage through the gastrostomy port; peritonitis - inflammation (caused by extravasation of gastric contents or food) of the membrane lining the abdominal wall, which then covers the abdominal organs; avulsion - the patient or caregiver himself/ herself inadvertently pulls the gastrostomy tube completely out; dermatitis - inflammation of the dermis caused by extravasation of gastric contents by the external orifice; and bleeding - haemorrhage through the external orifice of gastrostomy.

\section{Statistical analysis}

Categorical values were described by proportions and compared by chi-square test or Fisher's exact test, when appropriate. Continuous values were expressed by mean \pm standard deviation or median and minimum-maximum and compared by Student's $t$-test or the Mann-Whitney $\mathrm{U}$ test respectively.

In order to identify individual potential factors influencing the death prognosis associated with PEG at eight weeks follow-up, univariate Cox models were used. All factors with $P<0.20$ after univariate analysis were included in the multivariate Cox model to assess their independent prognosis effects. Then, a backward stepwise procedure was used to select the final Cox model, retaining only those factors with $P<0.05$. In the univariate as well as in the multivariate Cox models, hazard ratios (HR) and the respective $95 \%$ confidence interval $(\mathrm{CI})$ were reported. To evaluate the proportionality assumption and overall fit of the Cox models, graphics and tests based, respectively, on the scaled Schoenfeld and Cox-Snell residuals were examined. No serious violation of either the proportionality assumption or the overall fit of the models was observed. Overall survival was estimated by using the Kaplan-Meier method. All tests were two-sided and statistical significance was defined as a $P$ value less than 0.05 . The receiver operating curve (ROC curves) was applied to calculate the sensibility and specificity of predictors for short-term survival. The area under a ROC curve quantifies the overall ability of the predictor to discriminate between those individuals with the outcome and those without the outcome. The validity of the model was measured by means of the area under the receiving operating characteristic curve (AUROC). 
A model with AUROC above 0.7 was considered useful, while an AUROC between 0.8 and 0.9 indicated excellent diagnostic accuracy. The optimum cut-off value was chosen as the value with the best sensitivity and minimally acceptable specificity for predicting the outcome. The sensitivity, specificity, and likelihood ratio were calculated for various corresponding cut-off values.

Statistical analyses were performed using Stata 12.1 SE (StataCorp, 4905 Lakeway Drive College Station, Texas 77845 USA.

This study has been approved by the Ethics Committee, does not have any conflict of interest and was registered under CAEE number 66288617.3.0000.5192 in the Brazilian National Ethics Research System.

\section{RESULTS}

Of the 253 PEG procedures performed throughout the period of this study, 54 were excluded because they were outpatients or merely involved the replacement of a previous PEG tube. Among the 199 patients initially considered for this study, 49 were excluded because of incomplete data and one because of unsuccessful procedure, leaving a total of 150 cases to be included in the study (FIGURE 1). The demographics data for them are presented in TABLE 1. The patients' mean age was $77.8 \pm 15.9$ with female predominance $(53.3 \%)$. All patients received diet by a nasogastric tube because none of them could eat or be hand-fed. No patient returned to oral feeding. A total of $101(65.1 \%)$ patients had chronic comorbidities. As mentioned before, $87(58.0 \%)$ had blood hypertension; 51 patients had diabetes $(34.0 \%) ; 6(4 \%)$ had chronic renal disease; and 6 patients ( $4 \%$ ) had malignancy. Fifteen days before the procedure, $67(44.7 \%)$ of the 155 patients were breathing through a tracheostomy tube and $17(11.3 \%)$ through an orotracheal tube. In the last month, $86(57.3 \%)$ patients had been in an intensive care unit, and in the last two months, $6(4.0 \%)$ had undergone haemodialysis for renal insufficiency. Differences between groups according to the time of survival are shown in TABLE 1.

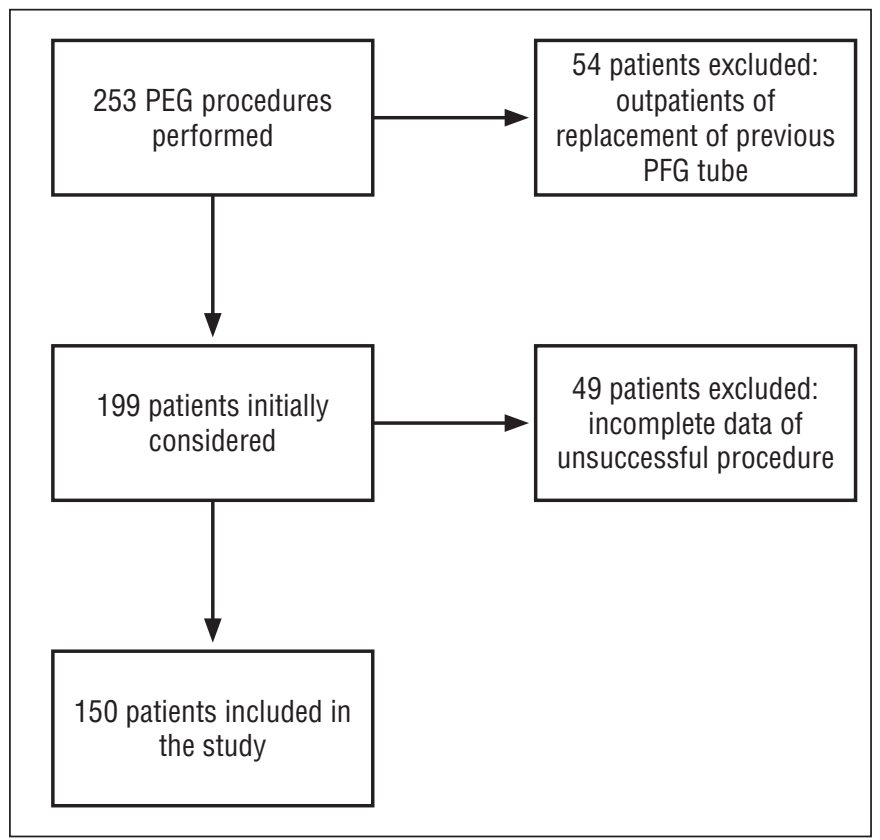

FIGURE 1. Flow chart of the patients selection.
TABLE 1. Baseline characteristics of patients.

\begin{tabular}{|c|c|c|c|c|}
\hline & $\begin{array}{l}\text { Overall } \\
(n=150)\end{array}$ & $\begin{array}{c}<8 \text { weeks } \\
\quad(n=28)\end{array}$ & $\begin{array}{c}>8 \text { weeks } \\
(\mathrm{n}=122)\end{array}$ & $P$ \\
\hline Male & $70(46.7 \%)$ & $12(42.9 \%)$ & $58(47.5 \%)$ & $0.654 *$ \\
\hline $\begin{array}{l}\text { Blood } \\
\text { hypertension }\end{array}$ & $87(58.0 \%)$ & $13(46.4 \%)$ & $74(60.7 \%)$ & $0.169 *$ \\
\hline Diabetes & $51(34.0 \%)$ & $9(32.1 \%)$ & $42(34.4 \%)$ & $0.818 *$ \\
\hline Dialysis & $6(4.0 \%)$ & $3(10.7 \%)$ & $3(2.5 \%)$ & $0.079 * *$ \\
\hline $\begin{array}{l}\text { Orotracheal } \\
\text { tube }\end{array}$ & $17(11.3 \%)$ & $3(10.7 \%)$ & $14(11.5 \%)$ & $1.000 * *$ \\
\hline $\begin{array}{l}\text { Internment } \\
\mathrm{UCI}^{\dagger}\end{array}$ & $86(57.3 \%)$ & $23(82.1 \%)$ & $63(51.6 \%)$ & $0.003 *$ \\
\hline Tracheostomy $^{\dagger}$ & $67(44.7 \%)$ & $18(64.3 \%)$ & $49(40.2 \%)$ & $0.021 *$ \\
\hline Age, y & $77.8 \pm 15.9$ & $81.8 \pm 11.8$ & $76.8 \pm 16.6$ & 0.135 \\
\hline Haemoglobin & $10.5 \pm 2.1$ & $9.3 \pm 1.7$ & $10.8 \pm 2.1$ & $<0.001$ \\
\hline Urea & $58.0 \pm 41.9$ & $76.6 \pm 58.2$ & $53.8 \pm 36.1$ & 0.009 \\
\hline
\end{tabular}

*Chi-square Pearson's test; **Exact Fischer test; $\dagger$ Preoperative period.

PEG tube placement was indicated for supporting patients with chronic neurodegenerative diseases such as Alzheimer's, Parkinson's, multiple sclerosis and amyotrophic lateral sclerosis $(90.6 \%)$, followed by tumours $(4.0 \%)$ and other causes $(5.3 \%)$, as shown in TABLE 2.

TABLE 2. Indication for the percutaneous endoscopic gastrostomy.

Overall $(n=150)$

Chronic neurodegenerative diseases*

$136(90.6 \%)$

Tumors

$6(4.0 \%)$

Others

$8(5.3 \%)$

*Such as Alzheimer disease, Parkinson disease, stroke, multiple sclerosis and sclerosis lateral amyotrophic.

\section{PEG-related complications}

Overall, 32 patients had PEG-related complications. Early complications during the first week following PEG were as follows: inadvertent tube avulsion, which occurred in $15(10.0 \%)$ patients, followed by buried bumper syndrome, in $8(5.3 \%)$ patients, abscess in $4(2.7 \%)$, peritonitis in $3(2.0 \%)$, dermatitis in $1(0.7 \%)$, and bleeding in $1(0.7 \%)$. We did not change PEG tube due to any tube malfunction (TABLE 3).

After up to two weeks after the PEG placement procedure, $51(34.0 \%)$ were breathing through a tracheostomy tube and 12 $(8.0 \%)$ through an orotracheal tube, $54(36.0 \%)$ had been in intensive care units, and $14(9.3 \%)$ underwent haemodialysis for renal insufficiency.

\section{Survival}

For the whole group, the proportional mortality probability at one and two months was $10.86 \%$ and $16.4 \%$ respectively. Mortality related to PEG placement was $1.2 \%$. A total of 23 patients died after up to eight weeks (FIGURE 2). 
TABLE 3. Clinical outcomes and complications of percutaneous endoscopic gastrostomy.

\begin{tabular}{lcccc}
\hline & $\begin{array}{c}\text { Overall } \\
(\mathrm{n}=150)\end{array}$ & $\begin{array}{c}<\text { weeks } \\
(\mathrm{n}=28)\end{array}$ & $\begin{array}{c}>8 \text { semanas } \\
(\mathrm{n}=122)\end{array}$ & $\boldsymbol{P}$ \\
\hline Dialysis $^{\dagger}$ & $14(9.3 \%)$ & $5(17.9 \%)$ & $9(7.4 \%)$ & $0.140 *$ \\
Tracheostomy $^{\dagger}$ & $51(34.0 \%)$ & $14(50.0 \%)$ & $37(30.3 \%)$ & $0.048^{* *}$ \\
$\begin{array}{l}\text { Orotracheal } \\
\text { tube }\end{array}$ & $12(8.0 \%)$ & $4(14.3 \%)$ & $8(6.6 \%)$ & $0.238^{*}$ \\
$\begin{array}{l}\text { ICU } \\
\text { internment }\end{array}$ & $54(36.0 \%)$ & $14(50 \%)$ & $40(32.8 \%)$ & $0.087 *$ \\
$\begin{array}{l}\text { Buried bumper } \\
\text { syndrome }\end{array}$ & $8(5.3 \%)$ & $0(0.0 \%)$ & $8(6.6 \%)$ & $0.353^{*}$ \\
Abscess & $4(2.7 \%)$ & $1(3.6 \%)$ & $3(2.5 \%)$ & $0.566 *$ \\
Peritonitis & $3(2.0 \%)$ & $2(7.1 \%)$ & $1(0.8 \%)$ & $0.090^{*}$ \\
Avulsion & $15(10.0 \%)$ & $4(14.3 \%)$ & $11(9.0 \%)$ & $0.482^{*}$ \\
Dermatitis & $1(0.7 \%)$ & $0(0.0 \%)$ & $1(0.8 \%)$ & $1.000^{*}$ \\
Bleeding & $1(0.7 \%)$ & $0(0.0 \%)$ & $1(0.8 \%)$ & $1.000^{*}$ \\
\hline
\end{tabular}

*Fisher exact test; **Pearson chi-square test. $\dagger$ Postoperative period.

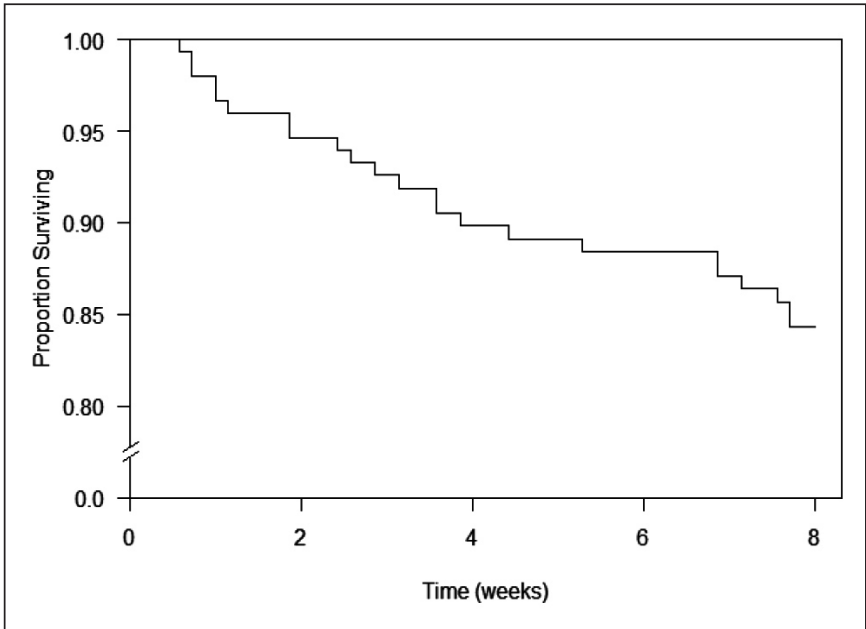

FIGURE 2. Kaplan-Meier graph showing 8-week survival.

\section{Variables associated with survival up to eight weeks}

Eight preoperative variables that are considered relevant for predicting survival at eight weeks were tested using univariate analysis. As shown in TABLE 4, haemoglobin, the history of dialysis, tracheostomy and ICU internment were considered significantly associated with survival up to eight weeks.

\section{Variables independently associated with survival up to eight weeks}

A multivariate analysis was performed by Cox regression for all variables. As shown in TABLE 5, significant independent association with survival up to eight weeks was found for haemoglobin and preoperative ICU internment by the final model.
TABLE 4. Univariate analysis of preoperative factors associated with survival at eight weeks.

\begin{tabular}{|c|c|c|c|c|}
\hline Variable & $\begin{array}{c}\text { Sample } \\
\mathbf{N}\end{array}$ & $\begin{array}{c}\text { Deaths } \\
\mathbf{N}\end{array}$ & HR (IC95\%) & $P^{*}$ \\
\hline $\begin{array}{l}\text { Neurodegenera- } \\
\text { tive diseases }\end{array}$ & 136 & $22(16.2 \%)$ & $2.30(0.3-17.06)$ & 0.353 \\
\hline Others & 14 & $1(7.1 \%)$ & 1.0 & \\
\hline \multicolumn{4}{|c|}{ Blood hypertension } & 0.276 \\
\hline Yes & 87 & $11(12.6 \%)$ & $0.63(0.28-1.44)$ & \\
\hline No & 63 & $12(19.0 \%)$ & 1.0 & \\
\hline \multicolumn{4}{|l|}{ Diabetes mellitus } & 0.987 \\
\hline Yes & 51 & $8(15.7 \%)$ & $1.01(0.43-2.38)$ & \\
\hline No & 99 & $15(15.2 \%)$ & 1.0 & \\
\hline \multicolumn{4}{|c|}{ Preoperative dyalisis } & 0.062 \\
\hline Yes & 6 & $3(50.0 \%)$ & $3.91(1.16-13.19)$ & \\
\hline No & 144 & $20(13.9 \%)$ & 1.0 & \\
\hline \multicolumn{4}{|l|}{ Tracheostomy } & 0.011 \\
\hline Yes & 67 & $16(23.9 \%)$ & $2.98(1.22-7.24)$ & \\
\hline No & 83 & $7(8.4 \%)$ & 1.0 & \\
\hline \multicolumn{4}{|c|}{ Preoperative ICU internment } & $<0.001$ \\
\hline Yes & 86 & $20(23.3 \%)$ & $5.63(1.67-18.94)$ & \\
\hline No & 64 & $3(4.7 \%)$ & 1.0 & \\
\hline \multicolumn{4}{|l|}{ Orotracheal tube } & 0.711 \\
\hline Yes & 17 & $2(11.8 \%)$ & $0.77(0.18-3.28)$ & \\
\hline No & 133 & $21(15.8 \%)$ & 1.0 & \\
\hline Haemoglobin & 150 & - & $0.60(0.49-0.83)$ & $<0.001$ \\
\hline
\end{tabular}

TABLE 5. Results of the adjustments of the initial and final Cox regression models to identify preoperative risk factors for mortality of PEG in patients.

\begin{tabular}{|c|c|c|c|c|}
\hline \multirow{2}{*}{ Variables } & \multicolumn{2}{|c|}{ Inicial model $(\mathrm{n}=150)$} & \multicolumn{2}{|c|}{ Final model $(n=150)$} \\
\hline & HR (IC95\%) & $P$ & HR (IC95\%) & $P$ \\
\hline \multicolumn{5}{|l|}{ Dyalisis } \\
\hline Yes & $2.34(0.65-8.39)$ & 0.191 & & \\
\hline No & 1.0 & & & \\
\hline \multicolumn{5}{|c|}{ Preoperative tracheostomy } \\
\hline Yes & $1.21(0.46-3.18)$ & 0.700 & & \\
\hline No & 1.0 & & & \\
\hline \multicolumn{5}{|c|}{ Preoperative ICU internment } \\
\hline Yes & $4.02(1.10-14.61)$ & 0.035 & $4.39(1.30-4.81)$ & 0.017 \\
\hline No & 1.0 & & 1.0 & \\
\hline Haemoglobin & $0.69(0.52-0.92)$ & 0.013 & $0.66(0.50-0.87)$ & 0.004 \\
\hline
\end{tabular}

\section{ROC curve}

The receiver operating curve (ROC) for haemoglobin adjusted for 8 weeks of survival is shown in FIGURE 3. The area under the curve (AUROC) was 0.75 (0.6454 to $0.8528, \mathrm{CI})$, considered useful, but not excellent. Based on the ROC curve analysis, the optimum cut-off of haemoglobin was set at $10.05 \mathrm{mg} / \mathrm{dL}$. A haemoglobin level less than 10.05 is related to short-term survival $(\mathrm{Se}=82.6 \%, 61.2 \%$ to $95 \% \mathrm{CI} ; \mathrm{Sp}=59.0 \%, 50.6 \%$ to $68.6 \%$, CI; likelihood ratio of 2.06 ). 


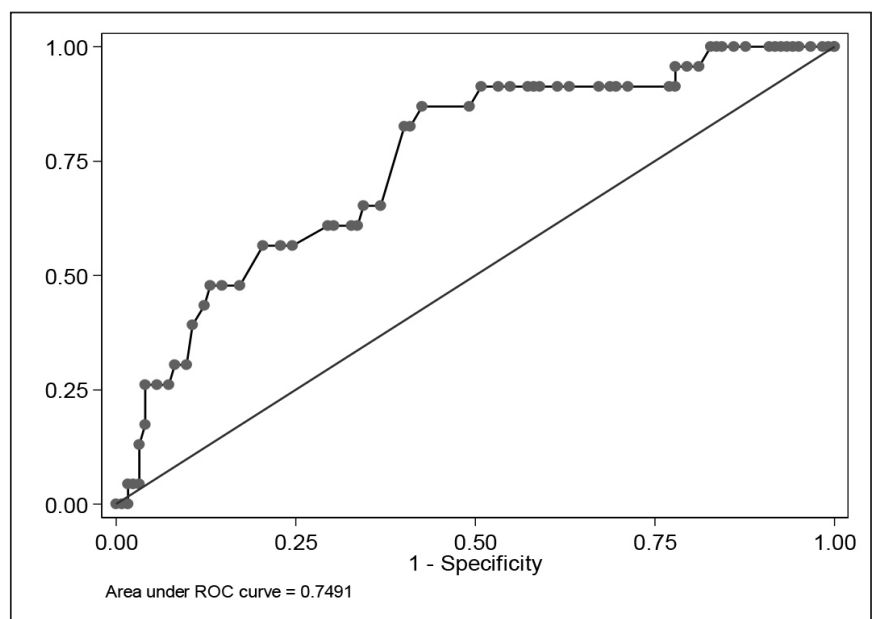

FIGURE 3. Receiver operating curve for haemoglobin as predictor of early mortality after PEG placement. The area under receiver operating curve was $0.7491(0.64$ to $0.85,95 \%$ CI) considered utile. The ideal area under the curve is 1.00 . The reference line represents that based on chance alone (area under the curve 0.50).

\section{DISCUSSION}

Providing food to people afflicted with chronic disease who are neither able to feed themselves nor be fed by hand seems a direct and simple choice since not providing food to these people means death by starvation, which is ethically, morally, and religiously unacceptable. However, this decision represents a major medical dilemma. A reasonable number of consistent studies have concluded that enteral feeding tubes can be inappropriate and deleterious for some patients ${ }^{(10,19-22)}$, especially older patients with dementia.

In spite of studies worldwide reliably revealing that devices used to provide enteral nutrition are associated with potential complications $^{(6,23)}$ and mortality ${ }^{(12,13)}$ and even though some studies have failed to show real benefits of enteral tubes ${ }^{(6,19)}$, there will be an occasion in the life of a chronic patient in which he/she will depend on long nutritional support and death does not appear to be imminent. In many countries, as in Brazil, relatives will not accept absence of feeding or insufficient oral feeding and rules to not spend time with the patient beyond the fear caused by religious, moral and ethical reasons ${ }^{(17)}$. In such instances, doctors will be stressed by relatives of the patients to prescribe PEG tube to end his/her starvation. Despite guidelines discouraging enteral nutrition ${ }^{(24)}$, doctors will prescribe nasogastric tube feeding, which can be continued for a few weeks. After this short period, the nasogastric tube must be replaced by a PEG tube or the patient must be orally fed.

The 30-day proportional mortality rate was $11.05 \%$, which was equivalent to the mortality rates - ranging from $1.5 \%{ }^{(25)}$ to $54 \%{ }^{(11)}$ (TABLE 4) - mentioned by other studies; similarly comparable was the mortality related to PEG insertion (1.2\%). Differences can be attributed to the authors' selection of populations with different numbers of severe patients, as well as features intrinsic to each medical service and population investigated. Sanders et al. ${ }^{(11)}$ found an initial mortality of $28 \%$ at thirty days post gastrostomy, but patients with dementia had a mortality of $54 \%$ at one month. These results are higher than those commonly published and inevitably lead us to inquire whether these authors would not be indicating the procedure to end-of-life patients.
Eight weeks after PEG, 23 patients had died. We considered that the patients who died up to eight weeks following PEG insertion had a futile indication for PEG because they were submitted to the risk, complications, and discomfort of an invasive procedure, and financial resources were spent. They could have had the nasogastric tube left in place or even had the nutrition discontinued for cases where he/she was at the threshold of his/her life. Defining a time that would characterize a bad indication for PEG is not a simple assignment. We chose eight weeks as the cut-off because although the nasogastric tube is recommended for short-term use, there may be special situations where a longer use of nasogastric access may be admitted. A patient with nasogastric access and risk factor for short survival may qualify as one such situation. We arbitrarily chose eight weeks as a reasonable time to extend the nasogastric tube in selected patients to avoid further risks of PEG access.

We found a rate of severe or simple complications that are comparable to those in the literature ${ }^{(11,26)}$. Sanders and colleagues ${ }^{(11)}$ reported on six cases of stomach bleeding that resulted in patient death. We did not observe gastric haemorrhage in our series, and we believe that this complication can be avoided with the dedication of the operative technique. Also, we did not observe tube blockage, because we insisted that the tube be supplied abundantly with water after the diet and that it be replaced every six months.

We found that haemoglobin and ICU staying on the third last day are preoperative independent risk factors associated with death after eight weeks. Although haemoglobin AUROC has been shown to be an acceptable but not excellent predictor, the haemoglobin value of $10.05 \mathrm{~g} / \mathrm{dL}$ provides reasonable sensitivity and specificity on which to base the medical decision. Patients who were hospitalized in the ICU in the days leading up to the procedure are obviously frail patients with chronic conditions or illnesses, are poised at the end of their lives and should not be indicated for PEG.

Many authors have been concerned with identifying risk factors for PEG death in groups of patients such as patients with dementia, those with neurological diseases, with cranioencephalic trauma, or in non-secreted samples at short or long term.

Diabetes mellitus ${ }^{(27)}$, chronic obstructive pulmonary disease, hypo albuminemia ${ }^{(16,28,29)}$, neoplasms ${ }^{(23,26,30)}$, low transferrin and low cholesterol $^{(28)}$, nil by mouth more than seven days ${ }^{(31)}$, high serum creatinine $^{(27)}$, low IBM, past history of ischemic heart disease ${ }^{(27)}$, more than 1 cardiac factor ${ }^{(31)}$, abdominal pain and severe complications $^{(12)}$, neurological disease ${ }^{(23)}$, stroke $^{(32)}$, high C-reactive protein ${ }^{(33,34)}$, inpatient ${ }^{(7,11)}$, and age ${ }^{(12)}$ have been concluded - by logistic regression analysis - to be independent risk factors associated with short- or long-term survival after PEG in retrospectives studies. Some findings are contradictory. Dong-jun Oh's ${ }^{(29)}$ study of patients older than 65 years found no difference in mortality and procedure-related complications compared to those of younger patients. Sobani Zan and colleagues ${ }^{(35)}$ studying patients over 100 years of age found no differences regarding the serious complications, success rate or patient mortality associated with PEG tubes and concluded that PEG tube can be administered with careful selection in patients older than 100 years.

These results show various risk factors related with mortality after PEG, and it is understandable and acceptable that they are different. The authors involved conducted investigations in heterogeneous populations, in hospitals with different characteristics, and with different protocols, so they investigated different outcomes in retrospective studies and consequently with many limitations. To our knowledge, this is the only Brazilian study to investigate short-term survival in patients with PEG. 
Although the authors identified distinct risk factors for mortality after PEG, these can be classified into two groups: those that indicate malnutrition (albumin, low IBM, anaemia, and starvation) or those that indicate patients with severe chronic diseases (AMI, DM, renal failure, and preoperative stroke ICU staying). These results urge us to reflect on the current guidelines for indication of PEG, especially in elderly patients with some degree of dementia. Most guidelines recommend oral feeding, even if this is time-consuming and demands constant support from caregivers, and they are based on the conclusion that elderly patients with eating limitations do not benefit from the procedure, resulting in them being exposed to the procedure risks, including high mortality. However, if elderly patients with eating problems are becoming malnourished at the time of tube feeding indication, it is natural to assume that attention and care to nutrition have failed in the weeks or months prior to tube feeding, probably because oral feeding, despite efforts to optimize it, was no longer able to meet the nutritional demands of the elderly. Indicating the PEG tube when the patient is already malnourished and has frail organic defences is to submit him/her to a high-risk procedure, and this appears to be a clinical mistake. Mitchell ${ }^{(19)}$ and colleagues investigated the timing for PEG indication after development of eating limitations using nationwide data and concluded that neither the insertion of PEG tubes nor the timing of insertion affects the survival of patients with advanced cognitive impairment from dementia and new eating problems. Although this is a relevant conclusion, the authors did not study the nutritional status or associated diseases of patients at different times of indication for PEG tube insertion, and this could have limited the conclusion. It may be more reasonable to indicate tube feeding when patients show the first signs of malnutrition or eating problems rather than definitively contraindicating enteral feeding or indicating it late. If indicated at this time of clinical evolution, the expected effects on the nutrition, well-being, and quality of life of patients that have not been established by current studies may perhaps be detected.

This study has certain limitations as well. First, it is a retrospective study, which lacks matched control group and randomization. Some information that we would have liked to evaluate - for example, albumin, nutritional status, medications used, and associated diagnoses associated - were missing and could not be investigated. The lack of these data did not let us study certain subgroups; therefore, results in patients with specific diagnoses could not be observed. Follow up of the patients was limited. Many patients died at home or at home nursing and were not autopsied, so there is no documentation on the cause of death, and death by aspiration pneumonia and other conditions related with PEG have not been studied. The study also does not consider the locoregional characteristics of the population. Many patients were cared for by their relatives at home. Often, healthcare providers at home are not optimally equipped to implement medical recommendations at the bedside. This has many consequences. Adequate care might not have been taken to avoid probe avulsion, buried bumper syndrome or aspiration pneumonia. If patients were kept in the nursing home under the care of professionals and under strict attention protocols, these complications would probably be less frequent than those observed. These facts limit the generalization of results. Our patients were hospitalized. These patients have a higher risk of death after $\operatorname{PEG}^{(7,11)}$. Finally, we studied a relatively small sample. Although the sample size is comparable to that of other published studies, a larger sample would give us greater confidence in the results.

In conclusion, based on the results presented and discussed above, anaemia and previous ICU admission are independent risk factors associated with eight weeks mortality after percutaneous endoscopic tube feeding. Patients who were anaemic and who had recently been admitted to the ICU should be given the indication for PEG to be discouraged. The clinical indication of PEG tube feeding should be rigidly evaluated in patients who are anaemics or have severe comorbidities. An early indication for enteral feeding in patients with eating disorders may be a clinical solution for high procedure-related mortality. Keeping all this in mind, future studies should address the issue of the timing for PEG indication carefully.

\section{ACKNOWLEDGEMENTS}

The authors would like to thank Dr. José Natal Figueiroa for their excellent technical assistance as statistical reviewer.

\section{Authors' contribution}

Miranda LE, Penha MCR, developed the research question and designed the study. Miranda ACG, Costa MWF, Amorim AO collected data. Lima DL, Miranda LE, Penha MCR contributed to the draft of the manuscript. All authors read and approved the final manuscript.

\section{Orcid}

Luiz Eduardo Correia Miranda. Orcid: 0000-0002-7450-3212. Ana Clara Galindo Miranda. Orcid: 0000-0001-6802-8032.

Matheus Wanderly Fernandes Costa. Orcid: 0000-0002-30128940.

Alexandre de Oliveira Amorim. Orcid: 0000-0002-6338-1897. Marcel Rolland Ciro da Penha. Orcid: 0000-0002-5781-6727. Diego Laurentino Lima. Orcid: 0000-0001-7383-1284. 
Miranda LE, Penha MRC, Miranda ACG, Lima DL, Costa MWF, Amorim AO. Fatores de risco associados a mortalidade precoce após gastrostomia endoscópica percutânea em pacientes em um centro terciário no Brasil: um estudo retrospectivo de sobrevida em um único centro. Arq Gastroenterol. 2019;56(4):412-8.

RESUMO - Contexto - A gastrostomia endoscópica percutânea (GEP) é o principal método aceito para a alimentação por sonda em um longo período. Objetivo - Investigar os fatores de risco associados à mortalidade precoce após a realização de GEP. Métodos - Análise retrospectiva de sobrevida em um centro terciário em Recife, Brasil. Prontuários de 150 pacientes submetidos a colocação de GEP forma revisados. Os dados foram analisados pelo método de Kaplan-Meier. Os modelos de regressão proporcional Multivariável de Cox também foram construídos para testar os efeitos da GEP na mortalidade. Resultados - Um total de 150 pacientes submetidos a GEP foram estudados (70 homens). Dos participantes, 87 (58\%) tinham hipertensão arterial; 51 (34\%) eram diabéticos; 6 (4\%) pacientes tinham doença renal crônica e $6(4 \%)$ tinham alguma malignidade. As doenças crônicas neurodegenerativas foram a indicação clínica mais comum para a GEP. As taxas de probabilidade de mortalidade proporcionais de 30 e 60 dias foram de $11,05 \%$ e $15,34 \%$ respectivamente. A análise multivariada por meio da regressão de Cox mostrou a hemoglobina (HR 4,39, 95\% IC: 1,30-14,81, $P=0,017)$ e a permanência em Unidade de Terapia Intensiva (UTI) (HR $0,66,95 \%$ IC $0,50-0,87, P=0,004)$ como preditores significantes de mortalidade precoce. O corte no valor da hemoglobina de $10,05 \mathrm{~g} / \mathrm{dL}$ mostrou uma sensibilidade de $82,6 \%$ (61,2\%-95\% IC) e uma sensibilidade aceitável de 59,0 (50,6\%-68,6\% IC), com uma taxa de 2,06 para a mortalidade em oito semanas. Conclusão - Em pacientes que foram submetidos a GEP para nutrição por um longo período, baixa hemoglobina e internamento em UTI antes do procedimento estão associados com o risco de mortalidade precoce. A GEP não deve ser indicada nesses casos.

DESCRITORES - Transtornos de deglutição. Desnutrição. Nutrição enteral. Estado terminal. Demência.

\section{REFERENCES}

1. Gauderer MWL, Ponsky JL, Izant RJ. Gastrostomy without laparotomy: A percutaneous endoscopic technique. J Pediatr Surg. 1980;15:872-5.

2. Gauderer M. Twenty years of percutaneous endoscopic gastrostomy: Origin and evolution of a concept and its expanded applications. Gastrointest Endosc. 1999;50:879-83.

3. DeLegge MH. Enteral Access and Associated Complications. Gastroenterol Clin North Am. 2018;47:23-37.

4. Prabhakaran S, Doraiswamy VA, Nagaraja V, Cipolla J, Macbean U, Evans D, et al. Nasoenteric tube complications. Scand J Surg. 2012;101:147-55.

5. Ribera-Casado JM. Feeding and hydration in terminal stage patients. Eur Geriatr Med. 2015;6:87-90.

6. Moran C, O'mahony $\mathrm{S}$. When is feeding via a percutaneous endoscopic gastrostomy indicated? Curr Opin Gastroenterol. 2015;31:137-42.

7. Niv Y, Abuksis G. Indications for percutaneous endoscopic gastrostomy insertion: ethical aspects. Dig Dis. 2002;20:253-6.

8. Hucl T, Spicak J. Complications of percutaneous endoscopic gastrostomy. Best Pract Res Clin Gastroenterol. 2016;30:769-81.

9. Mitchell, Susan L, Tetroe JM. Survival After Percutaneous Endoscopic Gastrostomy Placement in Older Persons. Journals Gerontol. 2000;55:M735-M739.

10. Candy B1, Sampson EL, Jones L. Enteral tube feeding in older people with advanced dementia: findings from a Cochrane systematic review. Int $\mathbf{J}$ Palliat Nurs. 2009;15:396-404.

11. Sanders DS, Carter MJ, D’Silva J, James G, Bolton RP, Bardhan KD. Survival analysis in percutaneous endoscopic gastrostomy feeding: a worse; outcome in patients with dementia. Am J Gastroenterol. 2000;95(6):1472-5.

12. Wirth R, Voss C, Smoliner C, Sieber CC, Bauer JM, Volkert D. Complications and Mortality After Percutaneous Endoscopic Gastrostomy in Geriatrics: A Prospective Multicenter Observational Trial. J Am Med Dir Assoc. 2012;13:228-33.

13. Arora G, Rockey D, Gupta S. High in-hospital mortality after percutaneous endoscopic gastrostomy: Results of a nationwide population-based study. Clin Gastroenterol Hepatol. 2013;11:1437-44.

14. Grant MD. Gastrostomies in older patients: the 1990 National Hospital Discharge Survey. J Am Board Fam Pract. 1998;11:187-92.

15. Galia RN, Melli RN, Negba RN, Ilana RN, Shlomit RN, Jaqueline S, et al Percutaneous Endoscopic Gastrostomy : High Mortality Rates in Hospitalized Patients. Am. J. Gastroenterol. 2000;95:128-32.

16. Nair S, Hertan H, Pitchumoni CS. Hypoalbuminemia is a poor predictor of survival after percutaneous endoscopic gastrostomy in elderly patients with dementia. Am J Gastroenterol. 2000;95:133-6.

17. O'Mahony S. Percutaneous endoscopic gastrostomy (PEG): cui bono? Frontline Gastroenterol. 2015;6:298-300.

18. Schwartz DB, Barrocas A, Wesley JR, Kliger G, Pontes-Arruda A, Márquez HA, et al. Gastrostomy tube placement in patients with advanced dementia or near end of life. Nutr Clin Pr. 2014;29:829-840.

\section{(c)) BY-NC}

19. Teno JM, Gozalo PL, Mitchell SL, Kuo S, Rhodes RL, Bynum JP, et al. Does feeding tube insertion and its timing improve survival? J Am Geriatr Soc. 2012;60:1918-21.

20. Ticinesi A, Nouvenne A, Lauretani F, Prati B, Cerundolo N, Maggio M, et al Survival in older adults with dementia and eating problems: To PEG or not to PEG? Clin Nutr. 2016;35:1512-6.

21. Goldberg LS, Altman KW. The role of gastrostomy tube placement in advanced dementia with dysphagia: a critical review. Clin Interv Aging. 2014;9:1733-9.

22. Nakanishi M, Hattori K. Percutaneous endoscopic gastrostomy (PEG) tubes are placed in elderly adults in Japan with advanced dementia regardless of expectations of improvement in quality of life. J Nutr Heal Aging. 2014;18:503-9.

23. Blomberg J, Lagergren J, Martin L, Mattsson F, Lagergren P. Complications after percutaneous endoscopic gastrostomy in a prospective study. Scand J Gastroenterol. 2012;47:737-42.

24. Cegelka A. American Geriatrics Society feeding tubes in advanced dementia position statement. J Am Geriatr Soc. 2014;62:1590-3.

25. Varnier A, Iona L, Dominutti MC, Deotto E, Bianchi L, Iengo A, et al. Percutaneous endoscopic gastrostomy: complications in the short and long-term follow-up and efficacy on nutritional status. Eura Medicophys. 2006;42:23-6.

25. Finocchiaro C, Galletti R, Rovera G, Ferrari A, Todros L, Vuolo A, et al. Percutaneous endoscopic gastrostomy: A long-term follow-up. Nutrition. 1997;13:520-3

27. Yokohama S, Aoshima M. Risk factors of early mortality after percutaneous endoscopic gastrostomy: a retrospective study. Nihon Shokakibyo Gakkai Zasshi. 2009; 106:1313-20.

28. Nunes G, Santos CA, Santos C, Fonseca J. SUN-PP086: Percutaneous Endoscopic Gastrostomy for Nutritional Support in Patients with Dementia. Clin Nutr 2015;34:S55-S56.

29. Oh DJ, Kim B, Lee JK, Kang HW, Kim JH, Lim YJ, et al. Can percutaneous endoscopic gastrostomy be carried out safely in the elderly? Geriatr Gerontol Int. 2016;16:481-5.

30. Fisman DN, Levy AR, Gifford DR, Tamblyn R. Survival after percutaneous endoscopic gastrostomy among older residents of Quebec. J Am Geriatr Soc. 1999;47:349-53.

31. Janes SEJ, Price CSG, Khan S. Percutaneous endoscopic gastrostomy: 30-day mortality trends and risk factors. J Postgrad Med. 2005;51:23-9.

32. Kara O, Kizilarslanoglu MC, Canbaz B, Arik G, Varan HD, Kuyumcu ME, et al. Survival after Percutaneous Endoscopic Gastrostomy in Older Adults with Neurologic Disorders. Nutr Clin Pract. 2016;31:799-804.

33. Lee C, Im JP, Kim JW, Kim SE, Ryu DY, Cha JM, et al. Risk factors for complications and mortality of percutaneous endoscopic gastrostomy: a multicenter, retrospective study. Surg Endosc. 2013;27:3806-15.

34. Blomberg J, Lagergren P, Martin L, Mattsson F, Lagergren J. Albumin and C-reactive protein levels predict short-term mortality after percutaneous endoscopic gastrostomy in a prospective cohort study. Gastrointest Endosc. 2011;73:29-36.

35. Sobani ZA, Tin K, Guttmann S, Abbasi AA, Mayer I, Tsirlin Y. Safety of percutaneous Endoscopic Gastrostomy Tubes in Centenarian Patients. Clin Endosc. 2018;51:56-60. 